\title{
Trabalho e Cultura na Cidade Portuária de Santos (Brasil), 1890-1920
}

\author{
Fernando Teixeira da Silva \\ Universidade Estadual de Campinas, Brasil \\ Maria Lucia Caira Gitahy \\ Universidade de São Paulo, Brasil
}

\section{Resumen}

Este artigo analisa o conflicto se desenvoveu entre os trabalhadores do porto de Santos (Brasil) sobre o controle da oferta de trabalho. Ele argumenta que as características do trabalho, pouca mecanização, intermitência da carga e mobilidade dos estivadores em várias ocupações, eles controlam o mercado de trabalho, o eixo central do conflito encenado no porto durante a primera metade do século XX. Ele también mostra os esfuerços do Estado e os empregadores para arrancar o controle dos trabalhadores que conseguiram establecer na oferta de trabalho.

Palabras claves: trabalhadores do porto,oferta de trabalho, conflito, Estado

\section{Abstract}

This article examines the conflict between the workers of the port of Santos (Brazil) over the control of labor supply. He argues that the type of work, little mechanization, intermittent load and mobility of dock workers in various occupations, they control the labor market, the central axis of the load, and mobility of the dockers in various occupations, they control the labor market, the central axis of conflict stagedin the port during the first half of XX century. It also shows the efforts of the State and employers to wrest control workers who had managed to stablish on the labor supply.

Keywords: hardworking port, ofert of work, conflit, Estates 


\section{Introdução: Diversificação social e reforma urbana}

To último quartel do século XIX, uma reestruturação produtiva mundial 1 amplamente conhecida como a "segunda revolução industrial", coloca na agenda de muitos países a necessidade de melhor articulação de uma crescente produção de matérias primas e alimentos com o mercado internacional. Foi esta demanda que levou à construção de ferrovias e portos em muitas áreas mais tarde conhecidas como parte do "terceiro mundo".

No caso do Brasil, a segunda metade do século XIX assiste a um processo de diversificação econômica e social, com a definição do país como exportador de café, que culmina com as reformas políticas corporificadas na abolição da escravatura (1888) e na proclamação da república (1889). A imigração e a formação de um mercado de trabalho livre, em um momento de intensa urbanização, são processos correlatos que levam adiante a criação de um espectro social mais complexo, no qual cabe salientar a emergência da classe operária. A construção de portos e ferrovias foi um dos primeiros empreendimentos a reunir um contingente significativo de trabalhadores livres. ${ }^{1} \mathrm{O}$ surgimento das fábricas veio a engrossar as fileiras dos operários, que não tardam a reconhecerse enquanto tais por meio da organização de um movimento próprio.

Santos, que então se torna o "porto do café", é um lugar privilegiado para o estudo destas transformações maiores que a sociedade brasileira atravessa. Com a sua definição como porta de saída de uma produção cafeeira em expansão e porta de entrada de maciça imigração, a cidade experimenta um acelerado processo de urbanização, que a leva a triplicar sua população no último quartel do século XIX e, após a construção da ligação ferroviária com o planalto e do porto modernizado, a triplicá-la novamente na virada para o século XX, dobrando-a outra vez até a Primeira Guerra Mundial. O pequeno porto de águas tranqüilas, permanecera até o século XIX sem maior expressão. Ainda em 1823 era uma vilazinha de 4.700 habitantes, dos quais 2.000 eram escravos e 2.700 livres; entre estes havia 1.400 mestiços, mulatos, cafusos e caboclos. Em 1839, quando foi elevada à categoria de cidade, ainda era "o tipo apurado de uma povoação colonial sem fortuna e as praias lodosas do porto... freqüentadas por bandos de urubus, davam a nota característica local". ${ }^{2}$

Durante a década de 1850, o café que vinha avançando no chamado "Norte" de São Paulo, toma a dianteira no movimento do porto. É um momento significativo, já que, em 1859, é apresentado um projeto de traçado da ferrovia Santos-Jundiaí, cujos trabalhos se completam em 1867. Com isto, estabeleceu-se um "tronco", trajeto obrigatório para o escoamento de todo o café do estado - com exceção do

\footnotetext{
Não ignoramos o debate a respeito da experiência dos escravos na formação da classe operária brasileira, mas este não será o foco deste artigo.

2 Guilherme Álvaro, A Campanha Sanitária de Santos. Suas causas e seus efeitos, São Paulo, Serviço Sanitário do Estado de São Paulo/Casa Duprat, 1919, p. 11.
} 
Vale do Paraíba - controlado pela São Paulo Railway Co., a poderosa "Inglesa", cujo monopólio quase secular só será rompido pela Sorocabana em 1937. Todas as demais ferrovias do estado carreavam café para esta "boca de funil" que o despejava em um único porto.

Assim, em contraste com a situação anterior, no último quartel do século XIX, a cidade agita-se - e não só pelas atividades econômicas. O porto, agora ativo, passa a ser um importante centro abolicionista e republicano. A cidade de Santos engajou-se ativamente nos movimentos pelas reformas políticas que trouxeram à luz, naquele período, uma sociedade mais complexa. É interessante observar, no entanto, que estas mudanças sócio-econômicas e políticas só são elaboradas no plano cultural no momento seguinte. De fato, a Santos do início do século XX assiste a um visível processo de construção de instituições, tanto de cima para baixo quanto de baixo para cima. São estas instituições que vão permitir à sociedade santista reorganizar-se e reproduzir-se, atualizando as transformações maiores que estava atravessando culturalmente e, enfim, equipar-se para enfrentar o século XX.

Uma referência obrigatória para qualquer análise da cultura santista do período é a imigração, que altera significativamente o perfil urbano da cidade, que se torna mais diverso e cosmopolita. ${ }^{3}$ As colônias imigrantes criaram uma série de clubes e associações voluntárias, religiosas ou não, visando suprir as necessidades de seus membros. Obviamente eram instituições policlassistas, sendo que, em seu interior, tensões de classe vieram à tona mescladas a atritos étnicos e culturais. ${ }^{4}$ Os imigrantes também trouxeram seus costumes e atividades de lazer. ${ }^{5}$ Ao lado das diversões populares, o Teatro Guarani, projetado e construído em Santos pelo engenheiro Garcia Redondo e decorado pelo pintor Benedito Calixto, ainda na década de 1880, visava atender às demandas de um público mais sofisticado, o que demonstra que os imigrantes não eram os únicos a criar instituições nesta cidade em transformação, e que outras afinidades, além das de ordem nacional, congregavam as pessoas. $\mathrm{O}$ teatro abrigava companhias dramáticas e concertos, incluindo, é claro, óperas. No entanto, abriu seu palco também para comícios abolicionistas e republicanos, festividades e reuniões promovidas por associações de classe. ${ }^{6}$

Ainda, como parte do processo de diversificação sócio-cultural, outras instituições de elite foram criadas no meio urbano santista. Basta ter em conta a

\footnotetext{
3 De acordo com o Censo de 1913, em 41 anos a população da cidade havia decuplicado atingindo 88.967 habitantes. Os imigrantes representavam $42,5 \%$ da população da cidade. De cada cem habitantes, vinte e cinco eram portugueses, nove espanhóis, três italianos e um turco ou japonês. Maria Lucia Caira Gitahy, Ventos do mar: trabalhadores do porto, movimento operário e cultura urbana em Santos, 1889-1914, São Paulo-Santos, Editora da Unesp/Prefeitura Municipal de Santos, 1992, p. 41.

4 Um registro destas tensões, no caso da Beneficiência Portuguesa de Santos, pode ser encontrada em M. Gitahy,Ventos do mar, pp. 42-43.

5 Até um Redondel de Touros foi aberto em Santos, em 1907, e touradas foram realizadas. A paixão ibérica parece ter esfriado no ambiente tropical, porque cedo o público cansou do espetáculo sangrento, e para manter o Redondel aberto, o dono teve que apresentar circo e ginastas, substituindo estas atividades, em 1908, pelo cinematógrafo ao ar livre. M. Gitahy, Ventos do mar, p. 44.

6 M. Gitahy, Ventos do mar, p. 44.
} 
Associação Comercial, congregando os empresários, os diversos clubes em que estes empregavam suas horas de lazer e as associações culturais e beneficientes, e até mesmo as associações femininas, como aquela presidida por Eunice Caldas. ${ }^{7}$ Outra instituição cultural que floresceu em Santos, no final do século XIX, foi a imprensa. Embora diversos jornais tenham circulado na cidade anteriormente, parece que só no último quartel do século XIX ofereceram-se condições mínimas para sua sobrevivência fora da capital do estado. Uma imprensa diversificada e multiforme afirmou-se, atingindo diferentes setores sociais.

Naquele momento, até mesmo o espaço da cidade vinha sendo alterado com o saneamento, a extensão do assentamento urbano na direção do Atlântico, a construção dos canais e a criação de novos bairros, expressando, enfim, uma estrutura social mais diversificada. Uma comunidade multicultural e multiétnica, baseada em afinidades de trabalho e de residência, assim como nos múltiplos constrangimentos da condição operária, desenvolve-se na cidade, oferecendo um solo histórico fértil ao florescimento do movimento operário. De fato, este nasce e adquire voz, deixando sua marca na cultura santista. Ainda na última década do século XIX, sociedades mutualistas, um centro socialista pioneiro no país e um "natimorto" partido operário socialista alternam-se com as primeiras greves. Mas é só com a chegada do século XX que os operários passam a construir organizações mais duradouras.

A própria organização do movimento operário parece fazer parte deste processo. Não queremos afirmar aqui que os militantes operários do início do século $\mathrm{XX}$, entre os quais predominava inclusive uma linguagem política anarquista e sindicalista revolucionária, tenham proposto qualquer tipo de institucionalização de seu movimento que implicasse concessão à sociedade que criticavam em bloco e que desejavam transformar. Pretendemos sublinhar, ao contrário, que a própria mobilização e a luta social requerem a construção de meios para a sua reprodução e a da crítica social que veiculam. Neste sentido, as sociedades operárias formadas no início do século XX têm por referência histórica tanto as lutas que se desenrolaram nos próprios processos de trabalho, no interior das empresas, quanto a constituição de bairros e comunidades operárias, espaços insubstituíveis para a formação e transmissão das tradições de luta locais.

Assim, durante os primeiros anos do século XX, a reforma urbana ${ }^{8}$ coincidiu com a tarefa igualmente trabalhosa de reconstruir as instituições no espaço da

\footnotetext{
Diretora do Grupo Escolar Cesário Bastos, uma das novas escolas públicas inauguradas pelo regime republicano, e irmã do médico e cientista Vital Brasil. A associação visava a instrução das moças e a assistência aos pobres e doentes.

8 Diversos títulos podem ser consultados hoje sobre a reforma urbana santista. Entre os mesmos, vale citar os trabalhos de Luiz Augusto Maia Costa, O ideário urbano paulista na virada do século. O engenheiro Theodoro Sampaio e as questões territoriais e urbanas modernas (1886-1903), São Carlos-São Paulo, RiMa/FAPESP, 2003, e "O moderno planejamento territorial e urbano em São Paulo. A presença norteamericana do debate da formação do pensamento urbanístico paulista, 1886-1919”, São Paulo, FAU/ USP, 2005 (tese de doutoramento); Sidney Piochi Bernardini, Os planos da cidade: as políticas de intervenção urbana em Santos de Estevan Fuertes a Saturnino de Brito, São Carlos/São Paulo, RiMa/FAPESP, 2006, e "Construindo Infra-estruturas, planejando territórios: A Secretaria de Agricultura, comércio e Obras Públicas do Governo Estadual Paulista”, São Paulo, FAU/USP, 2007 (tese de doutoramento).
} 
cidade para enfrentar os desafios da reestruturação social então vivida. Não apenas as elites engajaram-se nesta atividade fundamental para a atualização, na esfera da cultura, das transformações sócio-econômicas em curso. As chamadas "classes médias" ainda diminutas, mas em expansão, desempenharam importante papel nesta tarefa. Já os anseios da classe operária e sua resposta às profundas transformações do trabalho e do próprio espaço da cidade tomam forma em uma crítica generalizada a uma sociedade altamente excludente, cujo sistema político não admitia qualquer possibilidade de expressão popular. Para os fins deste trabalho, é importante assinalar que a formação da classe operária local, assim como a de outros grupos sociais associados à emergência de uma estrutura urbana mais complexa, ocorre no bojo de uma profunda transformação do espaço da cidade. O período assiste, por todo o Brasil, a reformas urbanas indispensáveis, colocadas na agenda social pela reestruturação da economia mundial então vivida. Requalificar as relações entre cidade e campo e os espaços produtivos no interior de ambos, assim como o lugar do país na divisão internacional do trabalho, não era apenas uma tarefa de construção física, mas também de construção de instituições sociais voltadas para a busca cultural e a redefinição das relações sociais. A origem das primeiras escolas de Engenharia no Brasil faz parte deste processo. ${ }^{9}$ Com isto, iniciam-se tanto o ensino superior de Engenharia, Arquitetura e Urbanismo, quanto as pesquisas ligadas aos materiais de construção, que, como veremos, tocarão até o movimento operário santista.

O esforço de diversificação social era bastante abrangente: era preciso criar os quadros superiores, os "oficiais" intermediários e um grande "exército" do trabalho, capazes de construir o conceito brasileiro de "cidade moderna." A definição dos requisitos de qualificação do trabalhador era uma preocupação recorrente da elite naqueles anos e concretizou-se não apenas nos cursos ministrados nas Escolas de Engenharia, mas também em Liceus de Artes e Ofícios ${ }^{10}$ e outras escolas profissionais destinadas a formar esses "quadros intermediários" do grande "exército do trabalho". ${ }^{11}$ Já na segunda metade do século XIX, consolida-se legalmente a emergência de um mercado imobiliário. Mas no final do mesmo, com o grande impulso construtivo, ocorre paralelamente o estabelecimento da indústria da construção civil em bases empresariais. A constituição deste ramo industrial é lenta e complexa, sendo que cada um de

\footnotetext{
9 A Escola Politécnica do Rio de Janeiro, proveniente de sucessivas reorganizações da Academia Real Militar, foi criada em 1874. Luiz Antonio Cunha, $A$ universidade temporã, Rio de Janeiro, Civilização Brasileira, 1980; a Escola de Minas de Ouro Preto foi fundada em 1875. José Murilo Carvalho, A Escola de Minas de Ouro Preto: o peso da glória, São Paulo, Editora Nacional/FINEP, 1978; a Escola Politécnica de São Paulo em 1894 Sylvia Fischer, "Ensino e profissão: o curso de engenheiros-arquitetos da Escola Politécnica de São Paulo", São Paulo, FFLCH/Departamento de História, USP, 1989 (tese de doutorado) e a Escola de Engenharia Mackenzie, em 1896. Maria Cecília Loschiavo Santos, Escola Politécnica (1884-1984), São Paulo, EPUSP, 1985.

10 O Liceu de Artes e Ofícios de São Paulo foi fundado em 1873 e ganhou novo prédio em 1900. Sobre seu papel na qualificação de trabalhadores para uma cidade em intensa urbanização, ver Maria Lucia Caira Gitahy,"Qualificação e Urbanização em São Paulo: a experiência do Liceu de Artes e Ofícios, 1873-1934” em Maria Alice Rosa Ribeiro (org.), Trabalhadores Urbanos e Ensino Profissional, Campinas, UNICAMP, 1986.

${ }_{11}$ Maria Lucia Caira Gitahy (org.), Desenhando a Cidade do Século XX, São Carlos, RiMa/FAPESP, 2005.
} 
seus setores tem seu próprio ritmo de formação. Ao mesmo tempo, formam-se paulatinamente os mercados de locações, terrenos e moradias. ${ }^{12}$

Estes processos mais amplos, aqui indicados sumariamente, tiveram características próprias nas diferentes cidades do Brasil. Maria Irene Szmrecsányi aponta que no Rio de Janeiro "o dinheiro e as políticas do Estado foram usadas promovendo serviços e obras urbanas", enquanto em São Paulo a opção adotada foi a promoção do café, englobando um complexo de atividades muito mais diversificado, que não dispensava a polarização de seu vasto hinterland pela metrópole em formação. Assim, os empresários da cidade de São Paulo encontraram "em seu próprio corpo excelentes oportunidades de investimento". ${ }^{13}$ Várias outras cidades foram igualmente transformadas. Basta lembrar que apenas o engenheiro Saturnino de Brito $^{14}$ elaborou planos urbanísticos gerais para cerca de 40 cidades brasileiras do período, entre elas, a cidade de Santos, na qual, de seu posto na Comissão de Saneamento do estado, comandou as obras da reforma urbana, a partir de $1905 .{ }^{15}$ Esta última cidade foi objeto de elaboração de planos urbanos desde 1892, sendo que apenas no início do século XX reúnem-se as condições econômicas e políticas para que efetivas intervenções urbanas concretizem uma ação mais ampla no corpo da mesma. Em cidades como Santos, reconstruiu-se o espaço público, disciplinou-se o padrão do assentamento, prescreveram-se áreas diferentes para as distintas funções, separaram-se os bairros proletários dos mais refinados e dos da classe média. Foi nestas cidades em transformação que o movimento operário nasce e adquire voz. Não é de admirar, portanto, que os trabalhadores da construção civil tenham ocupado um papel crucial tanto em tais cidades quanto neste movimento, entendido como parte essencial da formação da classe.

\section{A classe operária santista: o papel central dos trabalhadores do porto e da construção civil}

A construção civil e os transportes, como assinalamos, estiveram entre os primeiros ramos responsáveis por uma grande concentração de trabalhadores no Brasil, a partir do final do século XIX, quando se tornava imperativa uma melhor

\footnotetext{
12 Paulo Cesar Xavier Pereira, Espaço, técnica e construção, São Paulo, Nobel, 1988.

13 Maria Irene Szmrecsányi, "Rio e São Paulo” em Revista USP No. 17, São Paulo, 1993, pp. $202-219$.

14 Sobre o urbanismo de Saturnino de Brito, ver Carlos Roberto Monteiro de Andrade, "A cidade como um corpo são e belo" in Cidade e História, Salvador, ANPUR, 1992, pp. 77-81. Saturnino também atuou no saneamento de Campinas, Belém, Paraíba e Aracaju. Entre 1920 e 1929, abriu escritório de engenharia no Rio de Janeiro, onde elaborou muitos de seus projetos. Milton Vargas, "Obras de saneamento (abastecimento de água, esgotos e recuperação de terras) in Shozo Motoyama (org.), Tecnologia e industrialização no Brasil, São Paulo, UNESP/CEETEPS, 1994, p. 93. Outras referências ao engenheiro podem ser encontradas, por exemplo, em Candido Malta Campos Neto, "Os rumos da cidade: urbanismo e modernização em São Paulo", São Paulo, FAU/USP, 1999 (tese de doutoramento); e Cristina de Campos, Ferrovias e Saneamento em São Paulo. O Engenheiro Antonio Francisco de Paula Souza e a construção da rede de infra-estrutura territorial e urbana paulista, 1870-1893, São Paulo, FAU/USP, 2007 (tese de doutoramento) além dos trabalhos já mencionados de L. A. M. Costa, (2003 e 2005), e S. P. Bernardini, "Construindo Infra-estruturas, planejando territórios" y Os planos da cidade.

15 A respeito das reformas urbanas e saneamento das cidades paulistas promovidas pelo governo estadual durante o período, ver S. P. Bernardini Os planos da cidade.
} 
vinculação da economia brasileira com o mercado internacional, o que levou à construção de ferrovias e portos. Na medida em que crescia a importância do ancoradouro de Santos como principal força do desenvolvimento econômico local e elo de integração com outras regiões do país e do mundo, a cidade foi palco de acelerado processo de urbanização e correlato crescimento populacional. Tais fatores foram responsáveis por uma febre de construções públicas e particulares que, crescentemente, exigia uma força de trabalho numerosa e qualificada. Com efeito, os chamados "artífices" do setor de edificações exerceram destacado papel formativo no processo de constituição da classe operária santista.

\section{Os "artífices" da construção ${ }^{16}$}

Durante as duas primeiras décadas do século XX, os operários da construção civil foram o grupo mais combativo da cidade e com maior potencial associativo para manter a continuidade de determinadas lutas, entidades de classe e reivindicações. Cabe aqui analisar o lugar que ocuparam em uma cidade eminentemente portuária e na dinâmica do movimento operário santista. Um primeiro fator a ser destacado é a qualificação profissional dos artífices. Pedreiros e carpinteiros ocupavam posições estratégicas na "arte de construir": ${ }^{17}$ tinham conhecimentos básicos de geometria e cálculo matemático, eram peritos no manejo de esquadros, prumos e níveis, e faziam a leitura das indicações dos desenhos traçados para as construções. Pintores, estucadores e marmoristas nutriam veleidades artísticas e buscavam obter habilidades de modelagem, escultura e decoração.

Outro fator do elevado poder de barganha dos artífices era a peculiar estrutura do mercado e da indústria da construção. As edificações por encomenda no setor habitacional contavam com quantidade apreciável de pequenos empreiteiros e mestres de obras, em geral vulneráveis às greves. Uma vez que estes últimos assumiam contratos com prazos fixados para a entrega das obras e recebiam o pagamento depois do trabalho concluído, a demora na realização dos serviços implicava descapitalização de seus recursos, pois precisavam arcar com dívidas anteriormente assumidas. Se o mercado de trabalho era favorável aos artífices, os empreiteiros ou mestres de obras dispunham-se a resolver rapidamente as pendências com os operários contratados. ${ }^{18}$ Assim, firmas de pequeno porte tendiam a aceitar as condições estabelecidas pelos sindicatos a fim de evitar ou encurtar greves, geralmente parciais, "o que ocasionava rivalidades na classe patronal.... Eles [os construtores] não suportavam, por muito tempo, ver obras

\footnotetext{
16 Este item baseia-se, sobretudo, em Fernando Teixeira da Silva e Maria Lucia C. Gitahy, "O movimento operário da construção civil santista durante a Primeira Guerra Mundial, 1914-1918”, em História Social No. 3, IFCH/UNICAMP, 1996; Fernando Texeira de Silva, Operários sem patrões: os trabalhadores da cidade de Santos no entreguerras, Campinas, Ed. da Unicamp, 2003, capítulos 1 e 2; e M. L. Gitahy, Ventos do mar; "Os trabalhadores da construção civil na belle époque." II Congresso Brasileiro de História Econômica, UFF, Niterói, 13-16 de outubro de 1996.

17 João Freire, Anarquistas e operários. Ideologia, ofício e práticas sociais: anarquismo e o operariado em Portugal, 1900-1940, Porto, Afrontamento, 1992, pp. 87-89.

18 Sheldon Leslie Maram, Anarquistas, imigrantes e o movimento operário brasileiro, 1890-1920, Rio de Janeiro, Paz e Terra, 1979, pp. 51-52.
} 
paradas e outras trabalhando", afirmou um trabalhador em suas memórias. ${ }^{19}$ Os artífices, portanto, tinham razoável margem de manobra para restringir a produção, regular a oferta de trabalho, proteger certos ofícios, especificar o número de trabalhadores para realizar determinada tarefa, indicar a quantidade de aprendizes e ajudantes a contratar, limitar demissões e permitir a presença de delegados sindicais que inspecionavam as condições de trabalho e buscavam assegurar que somente os sindicalizados haviam sido contratados (closed shop).

No plano organizativo, os artífices de Santos, ao contrário de outras cidades no mesmo período, formaram sindicatos profissionalmente articulados por ramo econômico, agregando serventes, que desempenhavam tarefas menos qualificadas. Eles consideravam que, se todos os ofícios estivessem unidos em uma única entidade, as greves poderiam ser vitoriosas, os salários mais elevados e os códigos de conduta no trabalho reforçados, buscando então eliminar a organização isolada de ofícios ciosos de suas prerrogativas e características distintivas. Ao lado disso, os artífices da construção civil se empenharam em apoiar e organizar o movimento operário santista, constituindo-se no bastião do sindicalismo de ação direta, alicerçado em organizações federativas, como a Federação Operária Local de Santos (FOLS), fundada em 1907. ${ }^{20}$

No entanto, essa centralidade dos artífices na dinâmica da organização dos trabalhadores de Santos começou a declinar a partir da Primeira Guerra Mundial, quando a categoria enfrentou longa conjuntura de desemprego, redução salarial, fim do sistema de closed shop (controle do mercado de trabalho pelo sindicato) e perda de diversas conquistas. A guerra favoreceu alguns empresários da construção, os quais ensaiaram novas medidas para lidar com o "problema operário", destacando-se as medidas pioneiras de Roberto Simonsen, diretor da Companhia Construtora de Santos, criada em 1912. Apesar da crise, esta empresa experimentou aguda expansão em seus negócios, colocando-se em posição de liderança entre os demais construtores para adotar concertadas iniciativas patronais no enfrentamento dos atuantes sindicatos de trabalhadores da construção.

Até meados dos anos 1930, os artífices se depararam com uma série de fatores que desagregaram sua tradicional posição no movimento operário santista. Primeiro, a Companhia Construtora contou com favores do poder municipal que a colocou à frente na edificação de obras públicas, ${ }^{21}$ tornando-se na década de 1920 uma das maiores empresas do país no ramo. Segundo, a fundação, em 1917, do Centro dos Construtores e Industriais de Santos (CCIS) solapou o

\footnotetext{
19 "Memórias de Severino Gonçalvez Antunha", Santos, junho de 1968; Edgar Rodrigues, Nacionalismo e cultura social, 1913-1922, Rio de Janeiro, Laemmerts, s.d., p. 361.

20 Sobre a forte audiência dos apelos à ação direta entre os trabalhadores da construção, cf. Marcel van der Linden e Wayne Thorpe, "Essor et déclin du sindicalisme révolutionaire", en Le Mouvement Social No. 159, abril-junio, 1992.

21 Coraly Gará Caetano, Desvendando mistérios: Roberto Simonsen e a luta de classes, IFCH/Unicamp, 1994 (tese de doutorado).
} 
controle do mercado de trabalho pelos sindicatos, criando um sistema de cadastro, sem o qual os trabalhadores não teriam acesso aos canteiros de obras (open shop). Terceiro, a Companhia Construtora e o CCIS implantaram uma política inspirada no welfare privacy norte-americano, adotando medidas de benefício social, como fundo de pensões e assistência aos trabalhadores, o que se traduzia em uma tradicional política anti-sindical e contrária à intervenção do Estado nas relações de trabalho.

Por fim, a luta pela regulamentação das profissões de engenheiro e arquiteto ${ }^{22}$ introduziu, gradativamente, uma divisão do trabalho baseada em maior separação entre concepção e execução, assim como assinala a entrada da aplicação de conhecimentos científicos, com maior previsão e precisão no âmbito das atividades de construção. Ambos os profissionais passaram a ocupar um lugar privilegiado no mercado e no processo de trabalho e a atacar "o predomínio absoluto dos mestres de obras", conforme expressou o próprio Simonsen. ${ }^{23}$ A hierarquia em grandes firmas, como a Companhia Construtora de Santos, começou a se transformar com a introdução do par engenheiro com formação científica/mestre de obras qualificado para ler o desenho agora traçado com maior precisão e transmití-lo aos demais operários, paulatinamente divididos em diversas equipes executoras de operações manufatureiras.

O impacto dessas alterações na organização e mobilização dos artífices não foi nada desprezível. Em meados dos anos 1930, já pareciam longínquas as duas primeiras décadas do século XX, quando os trabalhadores da construção andavam bem calçados, orgulhavam-se de suas habilidades, freqüentavam cursos de desenho no sindicato, escreviam em efêmeros jornais operários, liam obras clássicas de sociologia na FOLS, onde, usando gravata, ensinavam o que sabiam aos jovens serventes de pedreiro. ${ }^{24}$ Eram longínquos também os dias em que as greves de pequena duração ou a ameaça de sua generalização proporcionavam o êxito completo das pautas reivindicativas.

$\mathrm{O}$ aparecimento dos grandes construtores e o fortalecimento do papel dos engenheiros e arquitetos nas construções foram fatores determinantes no processo de rearticulação dos termos em que estavam assentadas as relações entre artífices e empregadores em Santos. Muitos operários passaram a vender sua força de trabalho para uma grande firma do setor, a Companhia Construtora, no interior da qual a presença de engenheiros ampliava a margem das decisões técnicas e econômicas, articulando conhecimento técnico e poder econômico no âmbito da produção. Mesmo os artífices do setor de edificações, que permaneciam em contato direto com empreiteiros de menor porte, sofreram

22 Sylvia Fischer, Ensino e profissão: o curso de engenheiros-arquitetos da Escola Politécnica de São Paulo, São Paulo, FFLCH/Departamento de História/USP, 1989 (tese de doutorado).

${ }_{23}$ Roberto Simonsen, À margem da profissão: discursos, conferências, publicações, São Paulo, São Paulo Editora, 1932, p. 157.

24 "Memórias de Severino", 127. 
os efeitos das investidas dos grandes empresários, os quais buscaram subordinar os pequenos empregadores à sua intransigente política anti-sindical, derrotando várias greves entre as duas guerras mundiais. E, por fim, cabe destacar que foi neste contexto de enfrentamento do "empirismo" dos mestres de obras que Roberto Simonsen, também de forma pioneira, fez verdadeira profissão de fé do scientific management entre os empresários brasileiros, como forma de lidar com "o relacionamento inerentemente conflituoso entre operários e empregadores", como admitia. ${ }^{25}$

\section{Os portuários ${ }^{26}$}

A característica da maioria dos portos, no período estudado, era a dispersão física e institucional de suas unidades, sem a existência de um órgão centralizador, o que dificultava a formação de quadros permanentes de trabalhadores. Assim, o trabalho portuário se estruturou, via de regra, na presença de intermediários (empreiteiros de estiva, companhias de navegação, casas exportadoras etc.) que contratavam uma força de trabalho ocasional. Em Santos, porém, as disputas pelo controle da contratação dos trabalhadores adquiriram perfil peculiar, pois o porto se organizou de forma "atípica". A Companhia Docas de Santos, com o apoio do governo federal, logo monopolizaria todas as operações de carga e descarga realizadas em terra. Depois da greve pela jornada de oito horas, em 1908, somente os estivadores -que operavam no interior dos navios- não foram totalmente absorvidos pela Companhia Docas de Santos dentro do cais.

Assim, ao contrário dos complexos portuários fragmentados, a empresa não organizou a força de trabalho sob o sistema de trabalho ocasional: manteve um corpo permanente de trabalhadores, podendo discipliná-los de modo mais efetivo. Com efeito, de seis greves no porto entre 1889 e 1912, apenas a de 1889 trouxe resultados positivos aos trabalhadores. Nas demais paralisações, o padrão de relacionamento da empresa foi sempre inflexível: intransigência, contratação de levas de fura-greves e mobilização de vasto contingente policial.

Contudo, o controle da empresa encontrava limites na própria natureza do trabalho portuário. Os serviços de carga e descarga eram realizados por grupos (ternos) de trabalhadores em uma indústria em que a divisão técnica do trabalho e a maquinaria ocupavam papel pouco significativo. $\mathrm{O}$ envolvimento dos portuários nos ternos, a vastidão do porto e certo anonimato nele existente implicavam familiaridade e formação de redes informais, de cujos vínculos podiam depender a sobrevivência dos trabalhadores e o aprendizado de

25 John D. French, O ABC dos operários: conflitos e alianças de classe em São Paulo, 1900-1950, São Paulo, Hucitec/São Caetano do Sul/Prefeitura de São Caetano do Sul, 1995, p. 69; ver também Barbara Weinstein, (Re)formação da classe trabalhadora no Brasil (1920-1964), São Paulo, Cortez, CDAPH-IFAN/Universidade São Francisco, 2000.

26 A descrição que se segue baseia-se, principalmente, em M. Gitahy, Ventos do mar, e Fernando Texeira da Silva, Operários sem patrões; A carga e a culpa. Os operários das docas de Santos: direitos e cultura de solidariedade, 1937-1868, São Paulo/Hucitec/Santos, Prefeitura Municipal de Santos, 1995. 
formas secretas de resistência. As relações sociais também preexistiam àquelas estabelecidas no trabalho. Laços pessoais e familiares eram acionados desde o momento da contratação da força de trabalho, criando múltiplas lealdades e tradições de trabalho transmitidas de geração para geração, de modo que muitas famílias foram socializadas no porto, criando verdadeiras linhagens de militância e experiência sindical. Em suma, esses fatores de solidariedade criavam terreno propício à ação coletiva, como a interrupção quase instantânea do trabalho em todo o porto, às vezes sem qualquer organização prévia ou demandas oficialmente formuladas.

Já os estivadores lutaram feroz e exitosamente para escapar da enorme sombra monopolista da Companhia Docas. A cultura de ofício dos estivadores, seus hábitos e crenças estavam umbilicalmente associados à natureza ocasional do trabalho, ${ }^{27}$ cujos aspectos negativos, como a instabilidade da remuneração, podiam se converter em vantagens. Muitos estivadores não foram seduzidos pelo emprego permanente e regular. $\mathrm{Na}$ medida em que trabalhavam para diferentes empresas, não identificavam sua ocupação como parte de uma firma em particular, e seu senso de pertencimento estava mais identificado à profissão, fonte de orgulho e de um forte sentimento de independência.

A categoria deu início a uma longa luta pelo controle do mercado de trabalho, passando a exercer o closed shop a partir de 1930. Outro passo importante seria o controle do processo de trabalho, permitindo ao sindicato fiscalizar o modo pelo qual os serviços deveriam ser realizados. Tal situação colocava os estivadores em uma situação fora dos parâmetros convencionais da disciplina fabril, e as normas de trabalho que passaram a vigorar codificavam relações de poder de forma similar aos esforços dos operários qualificados para intervir na organização do trabalho. E, de fato, os estivadores impuseram e negociaram regras duradouras de trabalho para regular a contratação e o exercício dos serviços nos navios, fazendo diminuir a influência patronal.

A ampliação de seu poder se deu com uma série de conquistas que surpreende por sua longevidade. Ao lado da closed shop, a categoria organizou o trabalho em forma de rodízio para distribuir as oportunidades de emprego eqüitativamente entre todos os estivadores sindicalizados, o que começou a vigorar desde a Segunda Guerra. Assim, foram mitigados esquemas de favoritismo que privilegiavam uma minoria em detrimento da maioria na contratação diária dos trabalhadores. Outro passo decisivo foi dado em 1956, quando o Senado aprovou a lei que instituiu o rodízio entre contramestres. Com isso, os representantes dos armadores (as entidades estivadoras) perderam a prerrogativa de escolher seus prepostos, pois os próprios estivadores passaram a exercer essa função rotativamente pelo prazo de sessenta dias, dando a todos a oportunidade de maior remuneração que o

27 Gordon Phillips e Noel Whiteside, Casual labour: the unemployment question in the port transport indutustry (1880-1970), Oxford, Clarendon Press, 1985, p. 271. 
cargo lhes oferecia. Deste modo, era reforçado o orgulho dos estivadores de "não terem patrão", pois podiam ser, simultaneamente, trabalhadores, fiscais do sindicato e contramestres de seu próprio ofício, determinando quem deveria trabalhar, por quanto tempo e em que condições - temas em torno dos quais gravitavam os principais embates na complexa Babel dos portos. ${ }^{28}$

De um modo geral, como veremos a seguir, podemos afirmar que os artífices da construção civil estiveram para o sindicalismo de ação direta em parte da Primeira República, assim como os estivadores estiveram para o comunismo entre o final da Segunda Guerra e o golpe de 1964. Ambos, a seu modo, constituíram os principais grupos formativos da classe operária santista na primeira metade do século XX.

\section{Mercado de trabalho, processo de trabalho e movimento operário ${ }^{29}$}

Santos foi palco de algumas das primeiras greves no Brasil, como a de 1877, quando os carregadores de café paralisaram o trabalho por aumento salarial. Durante a década de 1890, a cidade registrava a maior ocorrência de greves (dez) no país, depois do Rio de Janeiro, e a paralisação de 1891 foi a primeira greve geral local no Brasil. Em meio a esses movimentos, entre outros fatores, os trabalhadores da cidade foram constituindo uma acentuada cultura associativa. No decênio de 1881-1890, por exemplo, havia em Santos 15 associações mutualistas, e 40 outras de 1891 a $1920 .{ }^{30}$ Há registros ainda de sociedades beneficentes, clubes, grupos dramáticos e de dança, entre outras, além de vários jornais operários. Embalados pelas perspectivas de ampliação da cidadania aos trabalhadores com a proclamação da república, alguns socialistas buscaram articular os campos político-parlamentar e sindical na defesa dos interesses dos trabalhadores. Já em 1889, Santos foi berço do primeiro círculo socialista brasileiro, cujos fundadores criariam, em 1895, o Centro Socialista de Santos, com o objetivo de formar cooperativas e fundar um partido socialista, tendo publicado o jornal $A$ Questão Social.

Em 1890, mestres da construção civil fundaram a União Operária, sociedade de caráter mutualista, que se fundiu, em 1896, ao Centro Socialista. Em abril de 1904, coube novamente aos operários da indústria da construção a criação da Sociedade Primeiro de Maio. Meses depois, outros grupos de trabalhadores organizaram a Sociedade Internacional União dos Operários, com o objetivo explícito de agrupar todos os trabalhadores da cidade, e não apenas uma categoria profissional ou indústria específica. Ambas as instituições nutriam divergências, mas também atuaram conjuntamente em alguns movimentos, como na greve portuária de 1905.

\footnotetext{
28 Howard Kimeldorf, Reds or rackets? The making of radical and conservative unions on the waterfront, California, University of California Press, 1988.

29 Este item tem por base as obras citadas na nota 32.

30 Tânia de Luca, O sonho do futuro assegurado: o mutualismo em São Paulo, São Paulo, Contexto, 1990 , p. 20.
} 
Em 1906 e 1907, em meio a vários movimentos grevistas, com destaque para a luta pela jornada de oito horas, em 1907, surgem os sinais mais evidentes da presença do sindicalismo de ação direta na cidade, sobretudo pelas mãos dos trabalhadores da construção, responsáveis, ao lado de outras categorias, pela fundação, em julho de 1907, da Federação Operária Local de Santos (FOLS), organizada por militantes da Primeiro de Maio, e mais tarde, da Internacional, que aderiram à "ação direta". Em 1912, com o desemprego grassando no porto, o movimento operário voltava-se para os trabalhadores da construção, organizados na FOLS, que congregava também canteiros, alfaiates, tecelões, metalúrgicos, maquinistas, carroceiros, ensacadores e carregadores de café, estivadores e doqueiros. Naquele ano, os trabalhadores santistas foram, seguramente, a principal base de sustentação da Confederação Operária Brasileira (COB), organização sindicalista revolucionária, que contava com 22.500 associados de Santos, agrupados na FOLS, 5 mil do Rio de Janeiro e 10 mil de São Paulo. ${ }^{31}$ Essa destacada presença dos adeptos do sindicalismo de ação direta no movimento operário santista tornaria a cidade conhecida como "Barcelona Brasileira". A FOLS se notabilizaria, em 1912 e 1914, pela campanha contra a carestia, mas uma forte reação policial se abateu sobre o movimento, levando à expulsão de vários militantes estrangeiros, sobretudo portugueses.

Mas foi no porto que, até a Primeira Guerra, as greves tiveram maior visibilidade e impacto público, registrando os embates mais acirrados e dramáticos. Numa economia voltada primordialmente para a exportação de café, os transportes, especialmente portos e ferrovias, tornavam-se um setor estratégico. Se o café deixasse de chegar a seus consumidores internacionais, a economia como um todo podia entrar em colapso. Assim, patrões e governo mostravam-se dispostos a tudo, indo da repressão à negociação. A situação dos portuários era ambígua. A posição estratégica do seu ofício aumentava-lhes o poder de barganha, mas, ao mesmo tempo, tinham de lidar com muitos interlocutores, quase sempre inflexíveis, como a gigantesca Companhia Docas, armadores, firmas exportadoras e o próprio Estado. Ao lado dessa Babel portuária de diferentes patrões e categorias profissionais, os trabalhadores se defrontavam com uma grande diversidade de tarefas, horários, remuneração e condições de trabalho.

Em 1889, os carregadores do porto fizeram uma greve contra a Associação Comercial, que reunia seus patrões (donos das casas exportadoras de café), uma vez que a CDS ainda empregava apenas os trabalhadores da construção do porto. Com a mediação do delegado de polícia e de cônsules, a greve foi rápida (seis dias) e vitoriosa, concorrendo para esse desfecho uma epidemia de febre amarela, que afetava a oferta de trabalhadores, as obras do porto e parte da safra de café à espera de embarque. Mas os portuários não teriam a mesma "sorte" nas paralisações seguintes. Em maio de 1891, quatro mil trabalhadores da cidade cruzaram os braços. A reação não tardou. Fura-greves, Força Pública e navios

31 S. Maram, Anarquistas, imigrantes, p. 56. 
da Marinha foram mobilizados. O excesso de oferta de força de trabalho no mercado começaria a exercer enorme efeito desagregador na organização dos trabalhadores, sobretudo entre os portuários.

O forte movimento abolicionista em Santos foi responsável pelo grande afluxo de ex-escravos na cidade, muitos dos quais formaram o quilombo do Jabaquara. Nesta ocasião, foram usados como fura-greves no porto. Nesta primeira grande paralisação do período, a utilização ideológica do abolicionismo foi fundamental para promover aquilo que os jornais portuários denunciaram com ênfase como "divisão dos trabalhadores por raça". Os exportadores de café alcançaram êxito ao apresentar o conflito entre grevistas e fura-greves como "preconceito de raça" de trabalhadores imigrantes frente a uma população com experiência recente na luta abolicionista, quando na verdade estava em questão o problema crônico do exército de reserva. $\mathrm{O}$ argumento serviu como justificativa para o isolamento, derrota e a repressão aos grevistas, que seriam a tônica nas greves portuárias seguintes. Tais movimentos seriam reiteradamente explorados pela Companhia Docas contra seus rivais na disputa pelo controle do processo de embarque e desembarque de mercadorias, como ocorreu na violenta greve geral de 1897, quando a empresa foi vitoriosa na luta contra os donos de trapiches e passou a processar todo o comércio aduaneiro no cais. Em 1908, também sob o argumento de que seus serviços eram de "utilidade pública", a empresa passou a executar todo o serviço de transporte do café no interior do porto, eliminado deste espaço carroceiros e carregadores de café.

Por outro lado, o poderio e a intransigência recorrentes da empresa, ao lado da repressão que sempre se abatia sobre os trabalhadores, contribuiriam para estreitar os laços de solidariedade entre os trabalhadores, dentro e fora do porto, atrair a simpatia popular para os movimentos grevistas e criar instituições capazes de organizar diferentes categorias, como a Sociedade Internacional União dos Operários e a Federação Operária Local de Santos, que empreenderam greves que chegaram a transpor as fronteiras locais, como a greve iniciada em 1905 pelos estivadores e a greve pelas oito horas, em 1908, que conquistaram a solidariedade de trabalhadores de São Paulo e Rio de Janeiro.

Nesse período inicial de formação da classe operária santista, que vai do final do século XIX às vésperas da Primeira Guerra, vários grupos de trabalhadores, experimentando diferentes situações com respeito ao mercado e ao processo de trabalho, vindos de diferentes experiências culturais e sociais - vida de agricultor numa vila de Portugal ou das Ilhas do Atlântico, escravidão no Brasil, outros contextos sociais europeus e asiáticos, gente com as mais acidentadas histórias de vida - foram capazes de construir juntos um movimento e uma classe cujo núcleo eram os trabalhadores do porto. De um modo geral, o movimento operário em Santos no período foi mais importante pela sua própria existência, do que por eventuais ganhos materiais. Direitos adquiridos e conquistas materiais não eram 
transformados em legislação e exigiam repetidas batalhas para vingar e durar. Os esforços constantes, freqüentemente deslizando para greves renhidas, sobre as quais aqui pudemos apresentar apenas um pálido perfil, criaram a aura de um movimento operário combativo e heróico em Santos.

O movimento operário santista só voltaria a se expressar com visibilidade nos anos 1919 e 1920, em meio a uma onda de greves que tomou conta dos principais centros urbano-industriais do país. Com a retomada do crescimento do setor da construção, os artífices voltavam a ser o grupo mais bem organizado e mobilizado da cidade, buscando articular novamente todo o movimento operário local, sob a orientação do sindicalismo revolucionário, corrente à qual se ligava explicitamente apenas a Sociedade União de Artes e Ofícios (sindicatos dos trabalhadores da construção). Mas foram estes, ao lado dos portuários, o alvo privilegiado da repressão policial, da reação dos empresários e de um xenófobo nacionalismo.

Nesta conjuntura, o sindicalismo de ação direta experimentou rápido declínio, dividindo espaço com outras correntes: cristãos, socialistas, comunistas (a partir da criação do Partido Comunista do Brasil em 1922) e, sobretudo, reformistas, os quais defendiam a intervenção do Estado no mundo do trabalho e passaram a ter influência crescente na década de 1920 entre estivadores, trabalhadores da Companhia Docas, carroceiros e ensacadores e carregadores de café. Todas essas categorias vinculadas ao porto foram precocemente as principais bases em Santos do "sindicalismo oficial" implementado pelo corporativismo do primeiro governo de Getúlio Vargas (1930-1945). Com efeito, logo após a revolução de 1930 que pôs fim à Primeira República, o sindicato dos estivadores se aproximou de setores do novo governo, nomeadamente os "tenentes", que defendiam o corporativismo sindical, e, como foi assinalado, conquistou a closed shop, eliminando, definitivamente, a concorrência imposta no setor pela Companhia Docas.

O corporativismo sofreu forte oposição dos comunistas, o que, durante algum tempo, contribuiu para o isolamento do Partido Comunista do Brasil (PCB) em relação à grande maioria de trabalhadores e sindicatos de Santos. Tal situação do partido passou a se alterar a partir do momento em que todos os sindicatos da cidade foram reconhecidos pelo Ministério do Trabalho. Sobretudo na conjuntura grevista de 1934 e 1935, o partido desenvolveu uma eficaz política de alianças que lhe permitiu, pela primeira vez, experimentar influência decisiva na maior parte das categorias profissionais e seus respectivos sindicatos, contribuindo para a crescente politização do movimento operário santista por meio de práticas e projetos alternativos que ameaçavam o nascente corporativismo.

Sua inserção entre os estivadores, particularmente a partir do final da ditadura do Estado Novo (1937-1945), esteve entre as principais bases da mais 
importante e bem sucedida experiência do PCB na cidade, cujos militantes deram várias demonstrações de enraizamento no cotidiano dos trabalhadores. Coube, sobretudo, aos comunistas "pacificar a estiva", ou seja, criar os principais mecanismos políticos, contratuais e institucionais que, como vimos, possibilitaram uma distribuição mais eqüitativa das oportunidades de emprego e de salário. Por meio da sua atuação, foram golpeados, em grande parte, alguns dos fundamentos do poder de várias direções do sindicato dos estivadores, as quais, por meio de mecanismos de troca de favores, violência e intimidação, mantinham o controle da organização da categoria em detrimento dos interesses de uma vasta parcela de trabalhadores.

Com efeito, o retumbante sucesso eleitoral do PCB entre os trabalhadores da cidade no imediato pós-guerra deu início à caracterização de Santos como "Moscou Brasileira" e "cidade vermelha". Sem dúvida, os estivadores e outros comunistas foram os grandes responsáveis pela consolidação de uma forte cultura de solidariedade em Santos. A mobilidade desses trabalhadores dentro e fora do cais, permitida pela natureza ocasional do trabalho, foi o ingrediente fundamental para o estreitamento dos laços entre porto e cidade, o que guarda estreita relação com as características urbanas de Santos.

Neste aspecto, cabe acrescentar que, de um modo geral, os portuários estabeleciam relações sociais tecidas no trabalho, nos espaços de moradia e nas redes familiares, o que fortalecia entre eles um sentido de comunidade e pertencimento a um grupo profissional específico. Por outro lado, a relação dos trabalhadores do porto com os de outros ramos nutria um forte sentido de coesão de classe. A quase ausência de um parque fabril, a força amalgamadora do porto no mercado de trabalho e a vizinhança entre trabalhadores e sindicatos, ocupando espaços comuns e em comum, foram, enfim, fatores determinantes para a construção de um movimento operário vigoroso e alicerçado em uma peculiar cultura de solidariedade que se expressava publicamente em momentos de mobilizações coletivas que ganhavam o espaço urbano. No entanto, esse mesmo espaço foi alvo de políticas de segregação social e fragmentação das redes de sociabilidade tão duramente construídas pelos trabalhadores.

\section{Conclusão: A presença do trabalho na cultura e no espaço urbano santista}

Já se destacou aqui a importância histórica das reformas urbanas que varrem a cidade de Santos nos primeiros anos do século XX, já que a modernização do porto interferiu diretamente na reorganização espacial da cidade. Baniam-se as vielas coloniais, construíam-se largas avenidas desobstruídas aonde pudessem passar as carroças repletas de mercadorias e os bondes puxados por muares. Assim, a reconstrução da paisagem social e cultural de Santos teve uma visível contraparte: o aspecto físico da cidade mudou também. Com o trabalho dos 
médicos da Comissão Sanitária, na década de 1890, o combate de epidemias abriu caminho para a conclusão das obras do porto e dos projetos de reurbanização que tiveram lugar no início do século XX.

No entanto, as reformas urbanas foram empreendidas, não apenas para oferecer melhores condições sanitárias aos habitantes de Santos ou mesmo uma imagem moderna de cidade ao mundo, já que um evidente processo de segregação sócioespacial tem lugar. Como afirma Gambetta:

$\mathrm{Na}$ inexpressividade das antigas cidades coloniais, senhores, escravos e pobres livres compartilhavam o mesmo diminuto espaço. Separava-os já uma evidente desigualdade perante a lei. Com o crescimento no início da república, contudo, consolidado o regime de trabalho livre, os bairros burgueses e operários foram se destacando. Ganhavam contornos próprios, apartando pessoas que, juridicamente iguais, se distanciavam apenas pela posição de classe. $^{32}$

Vários projetos foram delineados, desde o plano sanitário do engenheiro Estevan Antonio Fuertes, ${ }^{33}$ professor da Universidade de Cornell, contratado pelo governo do estado em 1892. Os relatórios apresentados pelo engenheiro traziam recomendações a serem implementadas de imediato para que a situação não piorasse, e um plano sanitário completo transformou-se em documento amplamente debatido no meio técnico-profissional brasileiro da época (Bernardini, 2006). Saturnino de Brito, partindo destas propostas e discussões, em 1898, projetara uma rede de canais a céu aberto que drenaria o solo úmido de Santos resolvendo, ao mesmo tempo, o problema das chuvas constantes e do esgoto.

Naquele ano, o plano foi considerado utópico, mas a prosperidade econômica trazida pelo café, assim como as mudanças políticas no governo federal e, especialmente no estadual, vieram a mudar este quadro. Em 1905, Saturnino de Brito assumiu a direção da Comissão de Saneamento, subordinada ao governo estadual, e detalhou um plano urbanístico geral que incluía, é claro, a rede de canais de drenagem mencionada acima, abrindo horizontes mais amplos para a expansão urbana de Santos. Os canais santistas reorganizaram a paisagem urbana criando novos espaços públicos que alteraram inclusive os padrões de sociabilidade tradicionais. Foi nas avenidas de Brito, aponta Carlos Roberto

32 Wilson Roberto Gambetta, "Desacumular a pobreza: Santos no limiar do século”, em Espaço e Debates No. 11, São Paulo, NERU, 1984, p. 17.

33 Estevan Antonio Fuertes, nascido em Porto Rico, graduou-se pelo Rensselear Polytechnic Institute, obtendo a seguir os títulos de Doutor em Medicina e Engenharia Civil. S. P. Bernardini, "Construindo Infra-estruturas, planejando territórios”, p. 87. Em 1892, quando foi contatado pelo governo estadual paulista levando em conta sua destacada atuação no saneamento de New Orleans, já desde 1873 era diretor e professor da Escola de Engenharia Civil da Universidade de Cornell. S. P. Bernardini, Os planos da cidade, pp. 386-387. 
Monteiro de Andrade, mais do que em parques ou praças, que novas formas de intercâmbio social vieram à luz.

Figura 1: A planta de Santos

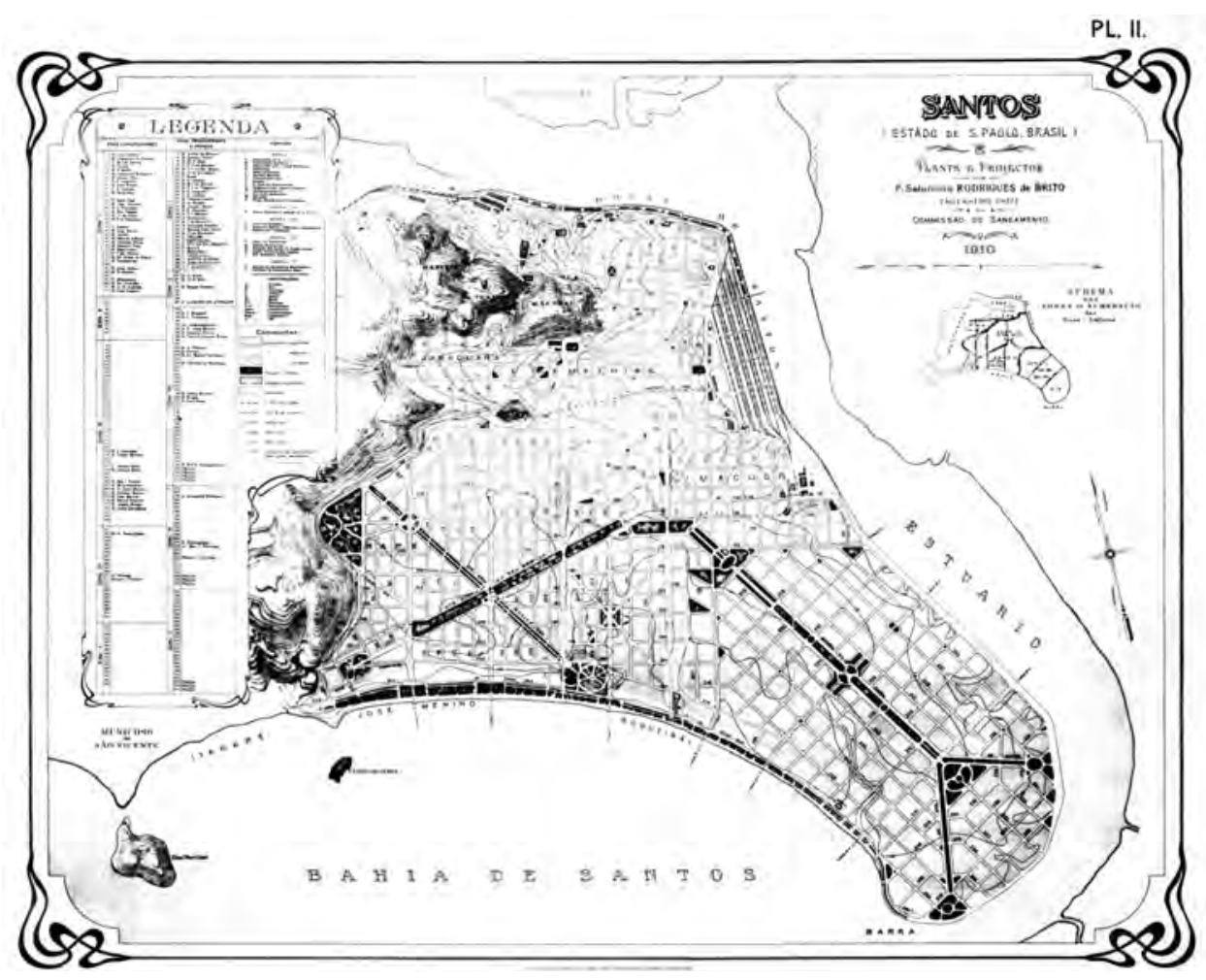

Fonte: S. R. de Brito, A planta de Santos, São Paulo, Typ. Brazil de Rothschild \& Co., 1915.

Não obstante, nos anos seguintes, tornaram-se freqüentes as discussões na Câmara Municipal sobre modificações na planta original para a expansão do sistema de esgotos. Na realidade, seria impossível implementar aquele projeto amplo, sem ferir interesses locais bem entrincheirados na Câmara Municipal. Assim, a planta original dos esgotos, proposta por Fuertes (e integrada a um plano urbanístico geral e construída por Brito), foi simplesmente ignorada, em diversas ocasiões, ao longo do tempo. De qualquer modo, é possível observar que o plano apresentado por Brito à Câmara Municipal, em 1910, chegou a ser parcialmente executado. Como bem observa Andrade ${ }^{34}$ :

34 Carlos Roberto Monteiro de Andrade, "O plano de Saturnino de Brito para Santos e a construção da cidade moderna”, en Espaço e Debates No. 34, São Paulo, NERU, 1991, p. 63. 
mesmo não tendo sido executado em todos os seus aspectos, não apenas temos a construção de uma cidade moderna, mas também a aplicação de princípios urbanísticos revolucionários para a época, onde o passado colonial da cidade desaparece em nome de um futuro marcado pela higiene e pelo progresso, que influenciará decisivamente o desenvolvimento do planejamento urbano no Brasil.

A despeito de tudo isto, Santos expandiu-se para leste na direção do Atlântico, graças à rede de canais, à abertura de novas avenidas e à linha de bondes (a burro). As antigas chácaras ali localizadas foram loteadas e, ambos, o aumento do comércio no velho Centro, perto do porto, e as medidas sanitárias, empurraram os moradores da área central para leste, onde novos bairros estavam sendo formados. Estes bairros eram: Macuco (que começa a ser povoado ainda na década de 1870); Vila Mathias (1886); Gonzaga, já à beira do Atlântico (1888); toda a área das praias do José Menino à Ponta da Praia (de 1900 em diante) e Vila Belmiro (de 1910 a 1915). Esta expansão seguiu um padrão descontínuo, e entre os bairros existiam enormes espaços desocupados, que eram usados como pasto para os numerosos animais, que continuaram a ser usados no transporte do café até o final da década de 1930.

Segundo Mazeviero, ${ }^{35}$ dois vetores distintos caracterizaram o crescimento urbano daquele período:

de um lado o vetor da exclusão ao qual pertenciam os trabalhadores, os imigrantes e os ex-escravos que passaram a ocupar a região central da cidade, as encostas dos morros e os arrabaldes mais próximos ao perímetro urbano. O vetor da exclusão compreende as zonas norte e noroeste de Santos e um pouco da zona central, que se torna quase que exclusivamente comercial. De outro lado, o vetor da valorização fundiária seguia os investimentos imobiliários ao longo da avenida Conselheiro Nébias seguindo em direção à praia da Barra, onde surgiam os primeiros casarões e palacetes da elite, além dos hotéis e dos clubes de luxo que transformavam a orla em um núcleo de lazer da nova cidade "modernizada". Esse vetor abarcava a zona sul santista. Portanto, a expansão urbana de Santos foi marcada pela cisão da cidade em dois núcleos sociais pelas reformas urbanas, pois na medida em que estas empurravam a população pobre para a periferia também criavam condições de ocupação e valorização da orla. Estas transformações que ocorreram na cidade foram comandadas pelo Estado e patrocinadas pelo capital oriundo do apogeu da economia cafeeira...

\footnotetext{
35 Maria Carolina Mazeviero, Memória e Identidade Urbana em Santos: usos e preservação de tipologias arquitetônicas da Avenida Conselheiro Nébias, São Paulo, FAU/USP, 2008 (dissertação de mestrado), pp. 46-47.
} 
A perspectiva do "embelezamento" tão característica das reformas urbanas da época vinha acompanhada de uma política de extermínio dos cortiços e outras construções populares que fugissem aos padrões da mesma. A população desalojada acabava sendo atirada à rua, e as prometidas vilas operárias não chegaram a ser construídas nem pelo governo do estado e nem pela municipalidade. Arranjando-se como podiam, os "desalojados" foram "empurrados" para os morros e bairros menos valorizados, ficando segregados da cidade moderna que se formava.

Um século depois, uma nova reestruturação produtiva em termos globais ("uma terceira revolução industrial"?) impacta de forma contundente o tecido urbano da cidade portuária. Contemporaneamente, entretanto, o que ocorre vai além de uma espacialização de mudanças na produção e/ou na distribuição. Em vários países, notam-se estratégias de planejamento urbano capazes de explorar novas possibilidades econômicas no corpo das cidades - mesmo a altos custos sociais para a maioria dos seus habitantes - operando com o pressuposto de que é necessário atrair os investimentos privados na renovação do espaço para garantir trabalho, pois, conforme o lugar, os lucros podem ser maiores.

Atuando nestes moldes, a prefeitura santista, na década de 1990, elaborou planos de reurbanização que apontam para a valorização imobiliária de áreas tradicionalmente operárias da cidade, sem quaisquer garantias de permanência dos atuais moradores e usuários das mesmas. ${ }^{36}$ Nestas condições, tal como ocorreu há um século atrás durante as reformas urbanas do passado, a efetivação do plano levará à gentrificação e à expulsão dos trabalhadores do local. Dentro destas propostas, apenas uma pequena área do centro velho será considerada como patrimônio histórico. Como bem aponta Mazeviero, ${ }^{37}$ "o reconhecimento de uma única área como detentora de memória pública pode funcionar como um instrumento que acentua e evidencia relações de exclusão e dominação cultural, já que quando se protege um bem também está sendo protegida a cultura e as práticas sociais por ele representadas".

O direito à cultura - hoje reconhecido como um direito universal a ser garantido pelo Estado - deve ser considerado na atuação dos órgãos que lidam com o patrimônio histórico e com o planejamento urbano, de modo a permitir uma reapropriação do espaço santista em que a manutenção da memória pública de um passado comum possa ser suporte de uma identidade urbana, em que a presença do trabalho é um valor tão significativo.

36 M. C. Mazeviero, Memória e Identidade Urbana em Santos, p. 150.

37 M. C. Mazeviero, Memória e Identidade Urbana em Santos, p. 151. 


\section{Bibliografía}

"Memórias de Severino Gonçalvez Antunha", Santos, junho de 1968; Edgar Rodrigues, Nacionalismo e cultura social, 1913-1922, Rio de Janeiro, Laemmerts, s.d., p. 361.

Barbara Weinstein, (Re)formação da classe trabalhadora no Brasil (1920-1964), São Paulo, Cortez, CDAPH-IFAN/Universidade São Francisco, 2000.

Candido Malta Campos Neto, "Os rumos da cidade: urbanismo e modernização em São Paulo", São Paulo, FAU/USP, 1999 (tese de doutoramento);

Carlos Roberto Monteiro de Andrade, "A cidade como um corpo são e belo" in Cidade e História, Salvador, ANPUR, 1992, pp. 77-81.

Carlos Roberto Monteiro de Andrade, "O plano de Saturnino de Brito para Santos e a construção da cidade moderna”, en Espaço e Debates No. 34, São Paulo, NERU, 1991, p. 63.

Coraly Gará Caetano, Desvendando mistérios: Roberto Simonsen e a luta de classes, IFCH/Unicamp, 1994 (tese de doutorado).

Cristina de Campos, Ferrovias e Saneamento em São Paulo. O Engenheiro Antonio Francisco de Paula Souza e a construção da rede de infra-estrutura territorial e urbana paulista, 1870-1893, São Paulo, FAU/USP, 2007 (tese de doutoramento) .

Fernando Teixeira da Silva e Maria Lucia C. Gitahy, "O movimento operário da construção civil santista durante a Primeira Guerra Mundial, 1914-1918”, em História Social No. 3, IFCH/ UNICAMP, 1996;

Operários sem patrões: os trabalhadores da cidade de Santos no entreguerras, Campinas, Ed. da Unicamp, 2003, capítulos 1 e 2;

Gordon Phillips e Noel Whiteside, Casual labour: the unemployment question in the port transport indutustry (1880-1970), Oxford, Clarendon Press, 1985, p. 271.

Guilherme Álvaro, A Campanha Sanitária de Santos. Suas causas e seus efeitos, São Paulo, Serviço Sanitário do Estado de São Paulo/Casa Duprat, 1919, p. 11.

Howard Kimeldorf, Reds or rackets? The making of radical and conservative unions on the waterfront, California, University of California Press, 1988.

João Freire, Anarquistas e operários. Ideologia, ofício e práticas sociais: anarquismo e o operariado em Portugal, 1900-1940, Porto, Afrontamento, 1992, pp. 87-89.

John D. French, O ABC dos operários: conflitos e alianças de classe em São Paulo, 1900-1950, São Paulo, Hucitec/São Caetano do Sul/Prefeitura de São Caetano do Sul, 1995, p. 69

José Murilo Carvalho, A Escola de Minas de Ouro Preto: o peso da glória, São Paulo, Editora Nacional/ FINEP, 1978

Luiz Antonio Cunha, A universidade temporã, Rio de Janeiro, Civilização Brasileira, 1980;

Luiz Augusto Maia Costa, O ideário urbano paulista na virada do século. O engenheiro Theodoro Sampaio e as questões territoriais e urbanas modernas (1886-1903), São Carlos-São Paulo, RiMa/ FAPESP, 2003.

"OO moderno planejamento territorial e urbano em São Paulo. A presença norteamericana do debate da formação do pensamento urbanístico paulista, 1886-1919”, São Paulo, FAU/USP, 2005 (tese de doutoramento); 
M. L. Gitahy, Ventos do mar; "Os trabalhadores da construção civil na belle époque." II Congresso Brasileiro de História Econômica, UFF, Niterói, 13-16 de outubro de 1996.

Marcel van der Linden e Wayne Thorpe, "Essor et déclin du sindicalisme révolutionaire", en Le Mouvement Social No. 159, abril-junio, 1992.

Maria Carolina Mazeviero, Memória e Identidade Urbana em Santos: usos e preservação de tipologias arquitetônicas da Avenida Conselheiro Nébias, São Paulo, FAU/USP, 2008 (dissertação de mestrado), pp. 46-47.

Maria Cecília Loschiavo Santos, Escola Politécnica (1884-1984), São Paulo, EPUSP, 1985.

Maria Irene Szmrecsányi, "Rio e São Paulo” em Revista USP No. 17, São Paulo, 1993, pp. 202-219.

Maria Lucia Caira Gitahy (org.), Desenhando a Cidade do Século XX, São Carlos, RiMa/FAPESP, 2005.

, Ventos do mar: trabalhadores do porto, movimento operário e cultura urbana em Santos, 1889-1914, São Paulo-Santos, Editora da Unesp/Prefeitura Municipal de Santos, 1992, p. 41.

,"Qualificação e Urbanização em São Paulo: a experiência do Liceu de Artes e Ofícios, 1873-1934" em Maria Alice Rosa Ribeiro (org.), Trabalhadores Urbanos e Ensino Profissional, Campinas, UNICAMP, 1986.

MiltonVargas, "Obrasdesaneamento(abastecimentodeágua,esgotoserecuperaçãodeterras)in Shozo Motoyama (org.), Tecnologia e industrialização no Brasil, São Paulo, UNESP/CEETEPS, 1994, p. 93.

Paulo Cesar Xavier Pereira, Espaço, técnica e construção, São Paulo, Nobel, 1988.

Roberto Simonsen, À margem da profissão: discursos, conferências, publicações, São Paulo, São Paulo Editora, 1932, p. 157.

Sheldon Leslie Maram, Anarquistas, imigrantes e o movimento operário brasileiro, 1890-1920, Rio de Janeiro, Paz e Terra, 1979, pp. 51-52.

Sidney Piochi Bernardini, Os planos da cidade: as políticas de intervenção urbana em Santos de Estevan Fuertes a Saturnino de Brito, São Carlos/São Paulo, RiMa/FAPESP, 2006.

, "Construindo Infra-estruturas, planejando territórios: A Secretaria de Agricultura, comércio e Obras Públicas do Governo Estadual Paulista”, São Paulo, FAU/USP, 2007 (tese de doutoramento).

Sylvia Fischer, "Ensino e profissão: o curso de engenheiros-arquitetos da Escola Politécnica de São Paulo”, São Paulo, FFLCH/Departamento de História, USP, 1989 (tese de doutorado)

Ensino e profissão: o curso de engenheiros-arquitetos da Escola Politécnica de São Paulo, São Paulo, FFLCH/Departamento de História/USP, 1989 (tese de doutorado).

Tânia de Luca, O sonho do futuro assegurado: o mutualismo em São Paulo, São Paulo, Contexto, 1990, p. 20.

Wilson Roberto Gambetta, "Desacumular a pobreza: Santos no limiar do século", em Espaço e Debates No. 11, São Paulo, NERU, 1984, p. 17. 